\title{
Gender differences: Participation in agricultural production in Ethiopia
}

\author{
Gudina Yadeta ${ }^{1}$, Gudina Abashula Fojo ${ }^{2}$ * \\ ${ }^{1}$ Assosa University. \\ PO Box 18, Assosa, Benishangul-Gumuz, Ethiopia \\ ${ }^{2}$ Jimma University. \\ PO Box 378, Jimma, Oromia, Ethiopia. \\ gyadeta12@gmail.com \\ * Corresponding Author
}

\section{ARTICLE INFO}

\section{Article History}

Received:

17 August 2019

Revised:

31 October 2019;

Accepted:

28 November 2019

\section{Keywords}

Agricultural

production;

Gender differences;

Paid and unpaid work

\begin{abstract}
Women occupy disadvantaged position despite their immense labor contributions to paid and unpaid activities. This study investigated gender differences pertaining to domestic and agricultural activities. The study employed a cross sectional survey design with a mixed research approach of data collection and analysis. Among 17th kebeles that are found in Yayo district, Witate and Hamuma were selected purposively. By doing so, among the total 2060 husbands and wives who live together, 324 of them were picked randomly by using Raosoft sample size determination formula. Descriptive statistics, independent T-test and chi-square were used as quantitative methods of data analysis were as thematic analysis was used as a qualitative method of data analysis. The study revealed that rural women had higher participation in agricultural activities such as weeding, threshing and storing, marketing and livestock management than men. Chi-square test showed that there were an association between gender and participation in decision making with regard to using agricultural inputs, poultry production and household expenditures. With regard to participation in human capitals such as training on agriculture and rural development, chi-square showed significant gender differences between responding husbands and wives. Therefore, it demands an effective policy intervention and awareness creation to address women's working conditions.
\end{abstract}

This is an open access article under the CC-BY-SA license. 


\section{INTRODUCTION}

The notion of gender has been given attention in agriculture owning to the existence of differences in contributing and benefiting from agricultural activities among men and women. Most of the time, ranges of women's work in the agricultural activities are considered as negligible in developing countries (Ghosh \& Ghosh, 2014). Yet, women's participation in agriculture is of paramount importance to intensify agricultural production and address the problem of food insecurity (Food and Agriculture Organization, 2011). This further contributes for poverty reduction, agricultural development and economic growth in developing countries (Grewal, Grunfeld, \& Sheehan, 2012). Women in developing countries cover about 43 percent of the agricultural labor force, ranging from 20 percent in Latin America to 50 percent in Eastern and Southeastern Asia and Sub-Saharan Africa (Food of Agriculture Organization, 2011). However, according to PalaciosLopez, Christiaensen, and Kilic (2017) their labor contribution in Africa is estimated ranging from 60 to 80 percent. Moreover, drawing on individual-disaggregated and plot-level labor input data from nationally representative household surveys in six Sub-Saharan African countries including Ethiopia. Palacios-Lopez, Christiaensen, and Kilic (2015) found that female labor participation in crop production alone is estimated to contribute 40 percent. However, women have less access to the productive resources and services in comparison to their counterparts (Food and Agriculture Organization, 2011; Okonya \& Kroschel, 2014; Mukasa \& Salami, 2015).

Agriculture encompasses the largest sector of Ethiopia's economy. It provides $73 \%$ of employment, $70 \%$ of the raw-materials for domestic manufacturing industries. Livestock production and food crops contributed the leading roles to agricultural growth in 2014/15 (Food and Agriculture Organization, 2017). However, country's agricultural development has faced obstacles from gender differences, land degradation and population growth which in turn lead to food insecurity and poverty (African Development Bank, 2004). In the country, food insecurity characterizes agricultural economy of the country owning to low productivity which is aggravated by storage related problems, high population growth, and workload on women. On the average, woman in the country has a working day of 12-14 hours (Cherinet \& Mulugeta, 2003). Rural women have much labour burden than that of their male counter parts owning higher unpaid household shores and responsibilities such as food prepara-tion and firewood collection (Food of Agriculture Organization, 2011).

Within the country, researchers such as Hailu, Abrha, and Weldegiorgis (2014), Ali (2014), Elias, Nahomi, Yasunobu, and Ishida (2014), Bassazenew (2008), and Kifle (2013), studied the role of women in agriculture and differential access to resources and assets among men and women in agricultural production. Their findings revolve around disparity in access to agricultural resources particularly among male and female household headed and its impact on productivity than focusing on differential engagement of husband and wife from the same household in agricultural and domestic activities. Women'slabour particularly the time they invest on different agricultural and domesticactivities was overlooked. Therefore, this study deals with participation of wives and husbands in productive as well as reproductive activities so as to investigate the relationship between gander and other variables such as paid work and unpaid work. By doing so, the objectives of the study were to assess men's and women's differential engagement in agricultural and domesticactivities; to describe factors that affect wives' and husbands participation in agricultural and domestic activities. The study has found that women's working condition is quite more complicated than that of their counterparts.

\section{METHOD}

\section{Study Area and Population}

This study was conducted in Yayo district which is found in Iluu Abba Bora zone of Oromia National Regional State. Iluu Abba Bora is located in southwestern part of Oromia National Regional State. It is bordered by KellemWollega zone in the West, Jimma zone in the east and Gambella region in the south.Yayo district covers the area of 84,626 hectares. It is situated at $564 \mathrm{~km}$ far away from 
Finfinne at Addis Ababa which is the capital city of the country (Yilmana Denesa Wereda Agricultural and Rural Development Office, 2017).

Generally, Yayo woreda had about 64,475 total populations from which 32,490 and 31,985 males and females respectively. Of these, urban area consists of 10,587 populations and 5,225 and 5,362 were males and females respectively. Rural area had 26,826 males and 27,148 females (Community-supported Agriculture \& World Bank, 2013). The number of females exceeds the number of their counterparts both in urban and rural areas. The study population for this research was 114 households (228 men and women individuals) in Witate and 48 households (96 men and women individuals) in Hamuma. Since the survey questionnaire is designed to assess participation in decision making for women in relation to men in their households, the primary female and male decision makers within the same household were selected. There are seventeen Kebele administrations in Yayo Woreda. Of these Kebeles, namely Hamuma and Witate were selected purposively to carry out the study. The reason behind the selection of these kebeles was due to the fact that these kebeles were model kebeles of the woreda in terms of progress in gender equality as preliminary information obtained from the Woreda Women's and Children's Affairs Office. Hence, these kebeles were selected to assess the extent to which there is equality in terms of participation and decision making in agricultural production based on empirical evidence.

\section{Sampling}

The study employed both probability and non-probability sampling technique. From nonprobability techniques, the researcher used purposive sampling to select the key informants and the FGD participants who provided rich in information regarding the study. For the probability sampling, sample size was determined by Raosoft's sample size determination formula at $95 \%$ confidence interval with $10 \%$ non response rate. The Raosoft sample determination formula obtained a sample size of 324 husbands and wives from the total 2060 respondents. Only, married couples who live together were included in the sample from both kebeles due to the nature as well as objective of the study. Hamuma and witate kebele had 308 and 722 households in which married husbands and wives were found respectively. Generally, there were 1030 households in both kebeles in which 2060 married husbands and wives live together. In order to get information from the sample individuals 324 peoples, systematic random sampling was used to select 162 households. Therefore, using this method enabled data enumerators to contact 324 married individuals who were living together. Then, the study population was divided into men and women and the sample size was calculated proportion to the number of usbands and wives in each kebele using stratified sampling technique. Finally, these primary male and female respondents from the same household were interviewed without depending on the notion headship. Data were gathered continuously for a month on April 1-30, 2017. Data enumerators interviewed observations unit (husband and wife) separately. They (data collectors) did it with pair across each household. Percentage of data used was $100 \%$ due to the nature of the study in which both husband and wife from the same household should be interviewed.

Tabel 1. Summary of the study population and the respective sample size

\begin{tabular}{llccccc}
\hline \multirow{2}{*}{ SN } & \multirow{2}{*}{ Kebele } & \multicolumn{2}{c}{ Husbands } & \multicolumn{2}{c}{ Wives } & Total Sample size \\
& & Total No. & Sample & Total No. & Sample & \\
\hline 1 & Hamuma & 308 & 48 & 308 & 48 & 96 \\
2 & Witate & 722 & 114 & 722 & 114 & 228 \\
& & 1030 & 162 & 1030 & 162 & 324 \\
\hline
\end{tabular}

Research Approach

This study mingled both quantitative and qualitative research approach to come up with reliable and valid findings about the study. The study is a mixed-method that examined how husbands and wives share participation in agriculture and domestic activities. Data collection (quantitative and qualitative) wasdone in parallel. 


\section{Source of Data}

This study used primary and secondary data. The primary data were gathered from both wife and husband in the same household. This was also supplemented by information collected from informants (FGDs and key informants), and records from FGDs informants. Key informant interview was employed to obtain depth information from relevant experts such as agriculture extension workers (2), expert from woreda's Agricultural and Rural development Office and kebele leaders (2) and expert from Woreda Rural Land Administration Office. Before conducting Focus Group Discussions, local authorities (kebele leaders) were approached for the selection of participants. Then, based on the given assistance from kebele leaders, participants were recruited from different isolated villages found within the two kebeles. Study population (sampled husband and wives) were not included in the FGDs. The informants were selected from the community based on the depth of their knowledge about the gender relation in agriculture. Elders (2), religious leaders (2), community leaders (2), women (4) and men (6) were participants of the Focus Group Discussions. After that, two FGDs were conducted relatively in comfortable and circle sitting. Each group contained eight individuals. Only one (FGD in Witate) was recorded besides taking notes. The other FGD in Hamuma was not recorded but note was taken from the discussion of discussants. Secondary data were collected from published and unpublished documents, reports from agricultural and rural development officers of the district.

\section{Methods of Data Analysis}

After collecting the data, the researcher analyzed it by using quantitative and qualitative methods of data analysis. The primary data from survey was analyzed and presented by using both descriptive and inferential statistical techniques. The method used is a two-group difference test using the independent $\mathrm{T}$ test technique. The descriptive and inferential data analyses were carried out by using SPSS 20 for windows. The former include tables and percentages, while the latter include Chi-Square test and independent T-test.

\section{FINDINGS AND DISCCUSIONS}

Participation in Productive and reproductive Activities

Among Maqi Oromo, Ethiopia, land preparation (clearing farm land, threshing floor) and sowing were the activities undertaken by men exclusively (Kifle, 2013). In this study, however; a very small number of respondents said that women participated in land preparation and sowing to some extent with their husbands (men). It is evident from the table 2 that majority $246(75 \%)$ of respondents said that husbands (men) alone participated in land preparation. Only 22(7\%) of respondents responded that sawing was performed by husband and wife jointly. About 265 (82\%) of respondents stated that husbands (men) alone participated in ploughing while $59(18 \%)$ of them responded others (husbands and sons) contributed in the same activity. No single woman was reported for having participation in ploughing. The same table also shows that men (husbands) dominated the selection of crop to grow as $249(77 \%)$ of respondents responded while $74(23 \%)$ percent of respondent said that husbands and wives selected the types of crops to grow on farming land jointly.

Weeding is one of agricultural tasks that women participate in widely (Kifle, 2013). Similarly, in this study respondents reported that husband and wife have done weeding jointly but women constituted the largest share in the activity. Of the 324 (100) husbands and wives, $11(3.4 \%)$ of them responded that wives alone perform weeding without other's assistance (household members). Harvesting and storing were the productive activities that husbands and wives done jointly. About $168(52 \%)$ and 217 (67\%) of husbands and wives said that they performed these activities together respectively. Sample respondents which accounts $38(11.7 \%)$ responded that wife alone do storing. These findings are relatively the same with the findings of (African Development Bank, 2004). Husbands and wives that accounts $138(42.6 \%)$ said that husband, wife and other family members participated in weeding whereas $67(20.7 \%)$ of them reported storing absorbed the labour contribution of husband, wife and other family members. Another productive activity in which 
farmers (sample respondents) in the study sites participated was herding cattle. As per to $68(18.8 \%)$ of respondents, husbands and wives engaged in herding cattle jointly while majority $101(31.2 \%)$ of respondents said husband, wife and other family members participated in the activity. Only two $(6 \%)$ of wife was reported in managing herding cattle lonely. The rest of respondents $161(49.7 \%)$ pursued their livelihood from farming only in Table 2.

Information from FGDs and key informants from both kebeles confirmed that farmers in the area have various roles which involve different activities in both productive and reproductive work. Men and women participate in agricultural activities including land preparation and clearing, ploughing, sowing weeding, pest and disease control, harvesting and storing. Most of these activities are performed jointly except ploughing, collection of coffee and sowing. FGDs informants further described preparation and clearing of land are the activities that are done with women to some extent but dominantly by men. The results presented in the Table 2 , shows that women dominated all domestic activities such as fetching water, collecting firewood, house cleaning, caring children, cooking, milking, gardening, and taking care of it for family members. On the other hand, men's (husband's) dominance of participation is observed in the some productive activities. These findings corroborate with the findings of (African Development Bank, 2004). In this study, cooking, milking, and house cleaning were domestic activities in which men (husbands) never participate. These activities were undertaken by women (wives) and others (children particularly daughters) exclusively (Table 2).

Tabel 2. Participation in Productive and Reproductive activities

\begin{tabular}{cccccc}
\hline $\begin{array}{c}\text { Productive and } \\
\text { Reproductive } \\
\text { activities } \\
\text { N=324 }\end{array}$ & $\begin{array}{c}\text { Husband } \\
\text { Alone }\end{array}$ & $\begin{array}{c}\text { Husband \& } \\
\text { wife jointly }\end{array}$ & $\begin{array}{c}\text { Wife } \\
\text { alone }\end{array}$ & $\begin{array}{c}\text { Husband, wife } \\
\text { \&F. members }\end{array}$ & Others \\
\hline $\begin{array}{c}\text { Land preparation } \\
\text { Selecting types of crop to }\end{array}$ & $246(75)$ & $7(2.2)$ & - & $9(2.8)$ & $62(19.1)$ \\
grow & $249(77)$ & $75(23)$ & - & - & - \\
Ploughing & $265(82)$ & - & - & - & $59(18)$ \\
Sowing & $290(89.5)$ & $22(6.8)$ & - & $10(3.1)$ & $2(.6)$ \\
Weeding & - & $170(52.5)$ & $11(3.4)$ & $138(42.6)$ & $5(1.5)$ \\
Harvesting & - & $168(52)$ & - & $152(47)$ & $4(1)$ \\
Storing & - & $217(67)$ & $38(11.7)$ & $67(20.7)$ & $2(.6)$ \\
Herding cattle & - & $58(18)$ & $2(.6)$ & $101(31.2)$ & - \\
Milking & - & - & $138(42.5)$ & - & $26(8.0)$ \\
Cooking & - & - & $279(86)$ & - & $45(14)$ \\
Collecting firewood & - & $21(6.5)$ & $209(64.5)$ & $19(6)$ & $75(23)$ \\
Fetching water & - & $9(3)$ & $204(63)$ & $24(7.4)$ & $87(27)$ \\
Taking grains to grinding & - & $18(5.6)$ & $271(83.6)$ & - & $35(10.8)$ \\
mills & - & $14(4.3)$ & $269(83)$ & - & - \\
Taking care of children & - & - & $245(75.6)$ & - & $79(24.4)$ \\
House cleaning & - & $39(9)$ & $277(85.5)$ & & $18(5.6)$ \\
Gardening and taking & & & & & \\
care of it & & & & & \\
\hline
\end{tabular}

Numbers outside and inside the parenthesis represents count and percentage respectively.

For instance, $271(83.6 \%)$ of the respondents said that taking grains to grinding mills was performed by wives alone, $35(10.8 \%)$ said wives and their daughters whereas the remaining 18 (5.6\%) said wives and husbands jointly took grains to grinding mills. The findings in the table 3 also indicate that taking care for children was dominantly undertaken by wives $269(83 \%)$ and both wives and husbands $16(4.9 \%)$. About $21(6.5 \%)$ and $9(3 \%)$ of respondents said that both wife and husband 
engage jointly in collecting firewood and fetching water respectively. Of the 324 (100), 209 (64.5\% and $204(63 \%)$ of respondent said that collecting firewood and fetching water were performed by wives respectively. According to (Ferrant, Pesando, \& Nowacka, 2014) women have higher participation and time devoted to reproductive activities. Furthermore, it has been stated as follows that every minute more that a woman spends on unpaid care work represents one minute less that she could be potentially spending on market-related activities or investing in her educational and vocational skills (Ferrant, Pesando, \& Nowacka, 2014).

In Ethiopia, the proportion of women's participation in fetching water and collecting firewood accounts 71 and 54 percent respectively. On the other hand, men's participation in both activities is only 29 and 28 percent respectively. Besides, the time spent on these activities is higher for women by more than seven hours than for men (Ferrant, Pesando, \& Nowacka, 2014). Respondents were asked to reply on how much hour they spent within twenty four hours/one day (only on the day of data collection). Accordingly, from the table (4.22) also showed that majority of women (46\%) spent three hours in a day in collecting firewood and water and 23.4 percent of them responded that they spent four hours a day whereas 7.4 and 2 percent spent five and six hours respectively. The remaining (23 percent) of women did not perform collecting firewood and water that day. Majority of men 155 (95.7 percent) did not participated in collecting firewood and water in that day.

Tabel 3. Average time woman spent in a day in the below selected activities

\begin{tabular}{|c|c|c|c|}
\hline Total $\mathrm{N}=162$ & Number of hours & Frequency & Percentage \\
\hline \multirow[t]{5}{*}{ Cooking } & 3 & 23 & 14 \\
\hline & 4 & 72 & 44 \\
\hline & 5 & 52 & 32 \\
\hline & 6 & 10 & 6 \\
\hline & 0 & 5 & 3 \\
\hline Total & & 162 & 100 \\
\hline \multirow[t]{6}{*}{ Fetching and collecting firewood } & 3 & 75 & 46 \\
\hline & 4 & 35 & 23.4 \\
\hline & 5 & 12 & 7.4 \\
\hline & 6 & 3 & 1.8 \\
\hline & 0 & 37 & 23 \\
\hline & & 162 & 100 \\
\hline \multirow[t]{5}{*}{ Care for child and elderly } & 5 & 29 & 18 \\
\hline & 6 & 29 & 18 \\
\hline & 8 & 8 & 5 \\
\hline & 10 & 4 & 4 \\
\hline & 0 & 91 & 56 \\
\hline Total & & 162 & 100 \\
\hline \multirow[t]{5}{*}{ Farming } & 1 & 7 & 7 \\
\hline & 2 & 11 & 7 \\
\hline & 3 & 12 & 7.5 \\
\hline & 0 & 132 & 81 \\
\hline & & 162 & 100 \\
\hline Social activities(like visiting neighbors & - & - & - \\
\hline Listening radio & - & - & - \\
\hline
\end{tabular}

It was only two $(1.2 \%, 2(1.2 \%, 2(1.2) \%)$ of men who spent half of an hour, an hour and 2 hours on collecting firewood and water respectively at that day. Husband respondents (98\%) did not spend on caring children while $5(2 \%)$ and $2(.7 \%)$ spent five and two hours on caring children and elders (Table 3). From the Table 3 explained it is evident that the division of labor between men and 
women tends to be unequal. Husbands never spent time in cooking whereas wives did not spend time on listening radio and social services at that day. Women are responsible for time taking activities such as cooking, collecting firewood and water and caring children and elder where as men undertake tasks that requires less time (farming). Men dominated farming where as women are mostly involved in domestic work.

Tabel 4. Average time man spent in a day in the below selected activities

\begin{tabular}{|c|c|c|c|}
\hline Total $\mathrm{N}=162$ & Number of hours & Frequency & Percentage \\
\hline Cooking & - & - & - \\
\hline \multirow[t]{4}{*}{ Fetching and collecting firewood } & $1 / 2$ & 2 & 1.2 \\
\hline & 2 & 2 & 1.2 \\
\hline & 2 & 2 & 1.2 \\
\hline & 0 & 156 & 96 \\
\hline Total & & 162 & 100 \\
\hline \multirow[t]{3}{*}{ Care for child and elderly } & 2 & 1 & .7 \\
\hline & 5 & 2 & 2 \\
\hline & 0 & 159 & 98.1 \\
\hline Total & & 162 & 100 \\
\hline \multirow[t]{11}{*}{ Farming } & 1 & 6 & 3.7 \\
\hline & 2 & 11 & 6.7 \\
\hline & 3 & 28 & 17 \\
\hline & 4 & 27 & 17 \\
\hline & 7 & 5 & 10 \\
\hline & 8 & 5 & 12 \\
\hline & 9 & 6 & 4 \\
\hline & 10 & 9 & 6 \\
\hline & 11 & 9 & 6 \\
\hline & 12 & 2 & 1.2 \\
\hline & 0 & 54 & 32 \\
\hline Total & & 162 & 100 \\
\hline \multirow[t]{5}{*}{ Social activities(like visiting neighbors } & 1 & 4 & 2.5 \\
\hline & 2 & 3 & 2 \\
\hline & 3 & 3 & 2 \\
\hline & 4 & 2 & 1.2 \\
\hline & 0 & 150 & 92.6 \\
\hline Total & & 162 & 100 \\
\hline \multirow[t]{3}{*}{ Listening radio } & 1 & 7 & 4.9 \\
\hline & $1 / 2 \mathrm{hr}$ & 3 & 2 \\
\hline & 0 & 151 & 93.2 \\
\hline Total & - & 162 & 100 \\
\hline
\end{tabular}

Listening radio is one of the means via information is disseminated for farmers (Ragasa, Berhane, Tedesse, \& Taffesse, 2013). From the above table all wives spent no time on social activities and listening radio. However information from Focus Group Disscusion with elders, community and religious leaders from both kebeles demonstrated that women are the back bone in the social activities like provision of help during emergency case including death. Without women, social event such as having contact with neighbor and wedding is absolutely futile. Kebele leader from Witate added the same message as follows “At community level, women's participation particularly in wedding and 
funeral ceremo-nies, Iddir, and daboo is so tremendous. They involved in all these activities through giving services such as preparing food, coffee and local beer, collecting firewood and water". However, community leaders in FGDs and agriculture extension workers from both kebele stressed that women's partici-pation in meeting and training is not as such promising as men because of their time constraining. In the following table 3 , it was only $4.9 \%$ of all respondents who responded that they had listened radio for an hour and only 2.5 percent of all respondents who engaged in social activities for an hour within 24 hours.

Women in developing countries are highly time constrained than men as a result of their engagement in unpaid house work (Malapit, Pinkstaff, Sproule, Kovarik, Quisumbing, \& MeinzenDick, 2017). On the average, woman in Ethiopia work 12-14 hours in a day (Cherinet \& Mulugeta, 2003). Unlike men, women work longer time which in turn impedes their decision making over labor intensive technologies and participation in human capitals such as training on agriculture and rural development (Mulema \& Damtew, 2016). With regard to time spent on collecting firewood and water, caring children and elder and farming, the independent t-test shows that means of the husbands and wives are significantly different at $p=.000$ (Table 5).Information with Kebele leader in Hamuma disclosed that wives handle almost all house-hold matters. They look after livestock, purchase goods and manage housework activities. On the average, they work 12-15 hours per day.

Tabel 5. Time Spent on Care for Children and Elderly, Farming and Collecting Water and Firewood in Hours per a Day

\begin{tabular}{|c|c|c|c|c|}
\hline \multicolumn{5}{|c|}{ Independent sample t- test } \\
\hline & $\mathrm{P}$ value & $\mathrm{T}$ & df & $\begin{array}{c}\text { Mean } \\
\text { difference }\end{array}$ \\
\hline $\begin{array}{l}\text { Time spent on care for children and elderly in hours per } \\
\qquad \text { a day }\end{array}$ & .000 & 10.150 & 322 & -2.53704 \\
\hline Time spent on farming in hours per a day & .000 & 10.456 & 322 & 3.06790 \\
\hline $\begin{array}{l}\text { Time spent on collecting water and firewood in hours } \\
\text { per a day }\end{array}$ & .000 & $\begin{array}{c}- \\
21.482\end{array}$ & 322 & -2.72840 \\
\hline
\end{tabular}

Level of Participation

The level of rural women's and men's participation in farming activities and domestic work were categorized in to different level of participation that ranges from not at all to the high level of participation. Table 5, presents the extent of rural husbands and wives involvement in some farming activities and domestic work. Accordingly, the chi-square was significant between the responding husbands and wives with regard to their participation in weeding $\left(\mathrm{X}^{2}=45.49, \mathrm{df}=3, \mathrm{p}=.000\right)$ (Table. 6). Therefore, weeding and gender are not independent; there is an association between the two variables in this study. The key informant interview (kebele leader) from Hamuma stated that: "Weeding, one of time taking activity in farming, is chiefly undertaken by women. The reason is that in the first place, weeding is boring activity that requires time and patience and the other is the influence of culture in which the activity (weeding) is mainly considered as women's work".

Concerning harvesting, there were no significant differences between responding husbands and wife in relation to participating in harvesting $\left(\mathrm{X}^{2}=.82, \mathrm{df}=2, \mathrm{p}>0.05\right)$ (Table 7). Therefore, harvesting and gender are independent of each other in this study. There was significant difference between responding husbands and wives with regard to participation in domestic work $\left(\mathrm{X}^{2}=223.2\right.$, $\mathrm{df}=3, \mathrm{p}=000$ ). The qualitative data from FGDs indicated that men have little or no participation in domestic activities because the gender division of labor in the community reserved these activities only for women. Hence, it is considered as shameful for men to engage in domestic activities. The chi-square showed significant differences between responding husbands and wives with regard to participation in storing $\left(\mathrm{X}^{2}=15.6, \mathrm{df}=3, \mathrm{p}=.001\right)$.Therefore, there was association between storing and gender. Information gained from FGDs informants from both kebeles indicated that storing crop production and particularly its management is dominantly done by wives (women). The information 
further reflected that since storing has strong connection with housework, it usually demands women's labour.

Table 7 depicts variation in the levels of contributions to farming decision in some activities by gender. The table shows that the contribution of husbands to agricultural input utilization was higher than that of wives. There was significant difference between responding wives and husbands with regard to decision making on agricultural inputs utilization $\left(X^{2}=90.46, \mathrm{df}=3, \mathrm{p}=000\right)$. Decision making on multiple cropping was low between both wife and husband respondents. Wife $113(69.7 \%)$ and husband $80(49 \%)$ respondents reported that they did not have decision on multiple cropping. The chi-square was significant at $\left(\mathrm{P}=.000, \mathrm{X}^{2}=19.7, \mathrm{df}=2\right)$ between husbands and wives on multiple cropping (Table 7). The same table shows that the contributions of wives to decision making on poultry production and household expenditure was principally higher than that of their husbands. There was significant difference between responding wives and husbands in relation to participation in decision making on poultry production $\left(\mathrm{X}^{2}=54.3 \mathrm{df}=3, \mathrm{p}=000\right)$. Qualitative information from FGDs from both kebeles indicated that the production and management of poultry (hen) is mostly performed by women as a result of cultural expectation. With regard to household expenditure, there was significant difference between responding wives and husbands in relation to participation in decision making on household expenditures $\left(X^{2}=204.1, \mathrm{df}=3, \mathrm{p}=000\right)$.

Tabel 6. Level of Participation in Some Farming Activities and Domestic Work

\begin{tabular}{ccccc}
\hline & & \multicolumn{2}{c}{ Respondents } & \multirow{2}{*}{ P value\& $\mathrm{X}^{2}$} \\
& Small extent & Wife & Husband & \\
level participation in & medium extent & $24(14.8)$ & $21(13)$ & \\
weeding & to a high extent & $133(82)$ & $78(42)$ & .000 \\
& Not at all & $0(0)$ & $4(2.5)$ & $X^{2}=45.49$ \\
& Total & $162(100)$ & $162(100)$ & \\
& small extent & $10(6)$ & $13(8)$ & \\
level participation in & medium extent & $35(21.6)$ & $39(24)$ & .663 \\
harvesting & to a high extent & $117(72)$ & $110(68)$ & $\mathrm{X}^{2}=.82$ \\
& Not at all & $0(0)$ & $0(0)$ & \\
& Total & $160(100)$ & $160(100)$ & \\
level of participation in & not at all & $0(0)$ & $98(60.5)$ & \\
domestic work & small extent & $5(3)$ & $38(23)$ & .000 \\
& medium extent & $18(11)$ & $10(6)$ & $\mathrm{X}^{2}=223.2$ \\
& to a high extent & $139(86)$ & $16(10)$ & \\
& Total & $162(100)$ & $162(100)$ & \\
level of participation in & small extent & $11(6.8)$ & $11(6.8)$ & \\
storing of crop production & medium extent & $101(62)$ & $106(65.4)$ & .001 \\
& to a high extent & $50(31)$ & $33(20)$ & $\mathrm{X}^{2}=15.6$ \\
& Not at all & $0(0)$ & $12(7.4)$ & \\
& Total & $162(100)$ & $162(100)$ & \\
\hline
\end{tabular}

Numbers outside and inside the parenthesis represents count and percentage respectively.

Information obtained from FGDs with community and religious leaders and key informants (agriculture extension workers and kebele leaders) from both kebeles on the degree of women's involvement in decision making disclosed that there was male dominance with regards to using on agricultural inputs particularly fertilizers. However, women do have high decision making contribution on household expenditure and poultry management. Accordingly, male dominance and belief system that stem from custom of the people including cultural norms and religion are the causes that peril the degree of women's involvement in decision making pertaining to farming related activities. 
Agriculture extension worker from Hamuma kebele stated that "even though women immensely participate on using agricultural inputs with their husbands, their decision making power is limited. Husband usually takes decision without considering the idea of his wife on using agricultural inputs".

Tabel 7. Wives' and Husband's Level of Participation in Some Farming Activities

\begin{tabular}{cccc}
\hline & & \multicolumn{2}{c}{ Respondents } \\
& & Wife & Husband \\
\hline using agricultural inputs & not at all & $11(6.7)$ & $5(3)$ \\
& small extent & $30(18.5)$ & $10(6)$ \\
level of participation in decision making on & medium extent & $109(67)$ & $63(39)$ \\
to a high extent & $12(7.4)$ & $84(52)$ \\
level of respondent's participation in decision & Total & $162(100)$ & $162(100)$ \\
multiple cropping & not at all & $113(69.7)$ & $80(49)$ \\
poultry production & small extent & $32(20)$ & $69(42.6)$ \\
& medium extent & $17(10.5)$ & $13(8)$ \\
& Total & $162(100)$ & $162(100)$ \\
level of respondent's decision making on & not at all & $23(14)$ & $59(36)$ \\
& small extent & $51(31.5)$ & $71(44)$ \\
household expenditure & medium extent & $54(33)$ & $30(18.5)$ \\
& to a high extent & $34(21)$ & $2(1.5)$ \\
level of respondent's decision making on & Total & $162(100)$ & $162(100)$ \\
& small extent & $5(3)$ & $98(60.5)$ \\
& medium extent & $34(21)$ & $41(25)$
\end{tabular}

Numbers outside and inside the parenthesis represents count and percentage respectively.

\section{CONCLUSION}

Based on the findings, the following can be concluded from the study. The time allocations within a day from the survey demonstrated the existence of difference in the participation of the husbands and wives in agricultural and domestic activities. This time allocation differences between men and women are greatly confined to gender based division of labor. The study also showed men and women participate in agricultural activities including land preparation and clearing, ploughing, sowing, weeding, harvesting storing and collection of coffee. Most of these activities are performed jointly except ploughing and collection of coffee. Yet, weeding, harvesting and storing absorbed women's labour immensely. In some activities such as preparation and clearing, and sowing, women did have minimal participation due to cultural expectations. On the other hand, regarding to reproductive activities such as gathering firewood and fetching water, women were responsible to them tremendously. Gender inequality in participation and division of labour at the household level were manifested. Women's double burdens in the household chores limited their participation in decision making pertaining to farming related issues, meeting and attending training program on agriculture. Therefore, it could be safe to conclude that working with all rural farmers in the study area in making men aware about the benefit of women's empowerment in agricultural production is imperative.

Suggestions from the results of the research are argued that creating favorable working condition for women by introducing labour save technology is one of the determinants in making them empowered. Yet, in this study, women were more exposed to time poverty than men mainly due to challenges related to time taking domestic activities. Hence, policy makers and NGOsshould consider the allocation of materials and financial resources for the introduction of technology, 
infrastructures and other important inputs for rural development services in the area. Furthermore, creating an enabling environment to challenge unfair gender roles is fundamentally crucial with regard to altering the usual gender division of labor. It will be imperative to work with rural communities as a whole by focusing on raising men's and women's awareness about the merit of gender equality in agricultural production.

\section{REFERENCES}

African Development Bank, (2004). Ethiopia multi-Sector Country Gender Profile.Agricultureand rural development North east and south region (ONAR).

Ali, H. (2014). An Assessment of women farmers' participation in agricultural extension services for income and nutrition improvement in Ethiopia: The case of Becho district, South West Oromia (Doctoral dissertation). Addis Ababa University, Ethiopia.

Bassazenew, A. (2008). Gender and agricultural production in Ethiopia: The case of Gozamen Woreda, Amhara Region (Doctoral dissertation). Addis Ababa University.

Cherinet, H., \& Mulugeta, E. (2003). Towards gender equality in Ethiopia. Stockholm: Swedish International Development Cooperation Agency.

Community-supported Agriculture \& World Bank. (2013). Ethiopia Rural Socio-economic Survey (ERSS). Addis Abeba and Washington. DC: CSA and World Bank.

Elias, A., Nohmi, M., Yasunobu, K., \& Ishida, A. (2014). Does gender division of labour matters for the differences in access to agricultural extension services? A case study in North West Ethiopia. Journal of agricultural science, 7(1), 138-147. doi:http://dx.doi.org/10.5539/jas.v7n1p138

Food and Agriculture Organization. (2011). The state of food and agriculture-women in agriculture closing the gender gap for development.

Food and Agriculture Organization. (2017). The future of food and agriculture: Trends and challanges. Rome.

Ferrant, G., Pesando, L. M., \& Nowacka, K. (2014). Unpaid care work: The missing link in the analysis of gender gaps in labour outcomes. OECD Development Center.

Grewal, B., Grunfeld, H., \& Sheehan, P. (2012). The contribution of agricultural growth to poverty reduction. Canberra, Australia: Australian Centre for International Agricultural Research (ACIAR).

Hailu, B. K., Abrha, B. K., \&Weldegiorgis, K. A. (2014). Adoption and impact of agricultural technologies on farm income: Evidence from southern Tigray, northern Ethiopia. International Journal of Food and Agricultural Economics (IJFAEC), 2(4), 91-106. doi:http://dx.doi.org/10.22004/ag.econ.190816

Kifle, D. (2013). Gender role in agricultural production in some parts of Ethiopia: A brief review. International Journal of Research in Applied, Natural and Social Sciences, 1(2), 49-52.

Malapit, H. J., Pinkstaff, C., Sproule, K., Kovarik, C., Quisumbing, A. R., \& Meinzen-Dick, R. S. (2017). The abbreviated women's empowerment in agriculture index (A-WEAI). IFPRI Discussion Paper 1647.

Mukasa, A. N., \& Salami, A. O. (2015). Gender productivity differentials among smallholder farmers in Africa: A cross-country comparison. African Development Bank.

Mulema, A., \& Damtew, E. (2016). Gender-based constraints and opportunities to agricultural intensification in Ethiopia: A systematic review. ILRI (aka ILCA and ILRAD). 
Okonya, J. S., \& Kroschel, J. (2014). Gender differences in access and use of selected productive resources among sweet potato farmers in Uganda. Agriculture \& Food Security, 3(1), 1-10. doi:https://doi.org/10.1186/2048-7010-3-1

Palacios-Lopez, A., Christiaensen, L., \& Kilic, T. (2015). How much of the labor in African agriculture is provided by women?. The World Bank.

Ragasa, C., Berhane, G., Tadesse, F., \& Taffesse, A. S. (2013). Gender differences in access to extension services and agricultural productivity. The Journal of Agricultural Education and Extension, 19(5), 437-468. doi:http://dx.doi.org/10.1080/1389224X.2013.817343

World Bank. (2015). The cost of the gender gap in agricultural productivity in Malawi, Tanzania, and Uganda (English). Washington, D.C.: World Bank Group.

Yilmana Denesa Wereda Agricultural and Rural Development Office Office. (2017). Unpublished document from Yayo District. 